\title{
DRAGONES Y SANTOS MILITARES EN LA HAGIOGRAFÍA BIZANTINA
}

\author{
Ángel Narro \\ Universitat de València. España.
}

Resumen: Este artículo analiza la relación entre dragones y santos militares en la hagiografía bizantina desde una perspectiva literaria. El análisis se centrará en las leyendas de San Teodoro o San Jorge, así como en milagros de San Menas o de Eugenio de Trebisonda.

Palabras clave: Hagiografía bizantina - Dragones - Santos militares

\section{DRAGONS AND WARRIOR SAINTS IN BYZANTINE HAGIOGRAPHY}

Abstract: This article examines the relationship between dragons and warrior saints in Byzantine Hagiography from a literary point of view. The analysis will be focused on the legends of St. Theodore and St. George and also in the miracles of St. Menas or St. Eugenios of Trebizond.

Keywords: Byzantine Hagiography - Dragons - Warrior Saints

Recibido: 03.07.2019 - Aceptado: 31.03.2020

\section{Correspondencia: Ángel Narro}

Email: angel.narro@uv.es

Profesor de Filología Griega

Universitat de València

Facultat de Filologia, Traducció i Comunicació

Departamento de Filología Clásica 
T a imagen del dragón alanceado por un soldado cristiano es, por su impacto visual, una de las más icónicas e identificables de la tradición hagiográfica en líneas generales. Además de a propósito de la representación de San Miguel, la fuente de inspiración para la creación de leyendas posteriores de este tipo, también es posible observar otros santos destacados del panorama hagiográfico bizantino como San Jorge o San Teodoro. El esquema clásico trata de evocar la victoria del cristiano sobre las fuerzas del mal, encarnadas en ese dragón cuyo aspecto feroz y oscuro o inmenso tamaño denota la calidad moral que representa frente a la santidad del oponente armado no solo con una pica o venablo, sino también con la simbología de la cruz ${ }^{1}$.

La representación iconográfica, además, se ve acompañada de relatos y leyendas acerca de la épica batalla entre el santo cristiano y el dragón que representa el diablo. Sus ecos remontan a la tradición mitológica antigua (Horus, Leviatán), en general, y griega, en particular (leyenda de Perseo).

Estos relatos sobre el santo que lucha frente al dragón, representación del mal, -en ocasiones puede tratarse también de una serpiente-, se introducen en la tradición cristiana en la breve alusión al dragón expulsado del cielo por el arcángel San Miguel en Apoc. 12, 7-9. Este pasaje es interesante por tres razones principales: 1) utiliza el esquema que protagonizará este estudio con el representante de Dios que lucha y acaba con el dragón, símbolo del mal; 2) hace referencia al "gran dragón" (ó $\delta \rho \alpha ́ \kappa \omega v$ ó $\mu \varepsilon ́ \gamma \alpha \varsigma)$, indicando claramente la relación dragón-diablo; 3 ) sienta las bases para la elaboración en la literatura cristiana posterior de episodios legendarios de carácter fantástico en los que se narra la épica batalla entre el dragón y el santo cristiano.

Desde este punto de partida, el objetivo del presente estudio se centrará en examinar la relación entre la serpiente y el santo militar en la tradición hagiográfica bizantina. Así, se pretende abordar la cuestión desde una perspectiva filológica, con el apoyo puntual de la iconografía cuando la situación así lo requiera. Esta atención a una tradición literaria concreta explica la ausencia del análisis del origen del motivo, para lo que se remite

1 La consideración negativa del dragón ( $\delta \rho \alpha ́ \kappa \omega v)$ o la serpiente (ő $\varphi ı$ ), utilizados en la lengua griega casi como sinónimos para aludir a un gran reptil, y su identificación con el demonio es un elemento esencial para entender este tipo de escenas y un tópico muy expandido entre los primeros cristianos (Quacquarelli, 1975; Grant, 1999: 2-5). 
a trabajos como el de Afhauser (1911), o de pasajes similares en otras obras bizantinas.

\section{Animales y santos}

El tratamiento de la cuestión animal en la literatura griega cristiana parece desarrollarse en dos sentidos distintos, aunque, sin duda, complementarios. Así, desde los Hechos apócrifos de los apóstoles escenas taumatúrgicas con animales como protagonistas son del todo habituales (Spittler, 2008; Narro, 2015). En la mayoría de casos, el apóstol emite una orden directa que el animal acata de inmediato, aunque también se registran escenas donde claramente la bestia parece renunciar a su naturaleza salvaje y manifestar, por inspiración divina, una especial devoción hacia este.

No obstante, en los Hechos apócrifos de los apóstoles también se registran escenas similares a la del dragón, en este caso con una serpiente, animal análogo, como protagonista. Según Merkelbach (1952) su presencia en las tres escenas en las que aparece, dos en los Hechos de Juan y otra en los Hechos de Tomás, se explica por la evocación del deseo sexual que representa la serpiente y su relación con el mal y el diablo. En la primera escena, la de los Hechos de Juan (75-76), la serpiente juega un papel ambivalente (Narro, 2015: 196-197), aunque, en cualquier caso, se somete a las órdenes del apóstol, sin que este acabe con su vida. En la segunda, la de los Hechos de Tomás (30-33), el apóstol se encuentra con el cadáver de un joven muerto por una serpiente que acaba tomando voz humana para mantener una larga conversación con él antes de que le ordene mostrar su verdadera naturaleza y succionar el veneno del cuerpo del muchacho para resucitarlo. En este caso, la serpiente acaba muriendo de forma brutal tras la orden de Tomás (Adamik, 2001; Narro, 2015: 200-202).

Las mismas pautas básicas de las escenas con animales que aparecían en los Hechos apócrifos de los apóstoles se siguen a grandes rasgos en el ámbito general de la literatura hagiográfica bizantina (Paschalidis, 2018). Aquí, como sucedía en el caso de los Hechos apócrifos de los apóstoles, se pretende evocar la armonía del hombre con los animales, en tanto que creaciones de Dios sometidas a este, según Génesis 1, 28. Se muestra así la paz universal entre los hombres y los animales de la que habla el profeta Isaías (Is. 11,6-9; 65,25). 


\section{Los primeros testimonios: San Teodoro y San Jorge}

El perfil de santo militar es uno de los mejor caracterizados entre las diferentes tipologías de santos en el Oriente tardo-antiguo y bizantino. Walter (1999) considera a Teodoro Terón como su prototipo y, en tanto que primer santo de estas características en el que se puede rastrear la historia del dragón, parece estar, sin duda, en lo cierto.

En líneas generales, se trata de personajes del primer cristianismo que pertenecían a la armada romana, algunos incluso generales, y que, o bien por su condición de cristianos, o bien por haberse convertido a posteriori, y ser obligados a venerar a los dioses paganos, son martirizados por su negativa a rendir culto a los ídolos. Si su perfil biográfico es más o menos claro, sus atributos post mortem también están bastante bien perfilados. A pesar de que, como cualquier otro santo o santa, puedan realizar curaciones -el caso más evidente sería el de Artemio-y otros milagros de tipo diverso -Demetrio de Tesalónica, Menas o los dos Teodoros-, en muchas ocasiones sus intervenciones están encuadradas dentro de lo que se podría considerar la esfera militar. Así, el santo aparece en batalla con atuendo militar, o protege a fieles o peregrinos que se dirigen a su santuario y que padecen algún tipo de percance o ataque en el que se acaba requiriendo su presencia.

Desde el punto de vista de la iconografía, la representación del santo militar también aparece bastante estereotipada (Walter, 2003). Existen, de hecho, dos tipos de imágenes prototípicas: el santo a pie o a caballo. En ambos casos, aparece con armadura o vestimenta militar, en la que se puede observar la cruz cristiana y porta una lanza en una de sus manos. La representación como soldado de infantería es mucho más hierática, la ecuestre, algo más tardía, muestra al santo en plena acción acabando con la vida de un dragón, símbolo del mal, o con algún otro enemigo -caso, por ejemplo, de San Demetrio alanceando al zar búlgaro Kalojan como en el milagro del santo narrado por Juan Estauricio a finales del siglo XIII-.

El episodio más célebre en el que un santo cristiano acaba con la vida de un dragón es, sin duda, el de San Jorge, cuyo paso a occidente garantizó la popularidad de esta escena gracias a la Leyenda áurea de Jacobo de Vorágine. Sin embargo, los datos apuntan a que la leyenda de San Jorge y el dragón sería una adición bastante tardía a su dossier (Festugière, 1971: 267). Así, si se tiene en cuenta que la representación de San Jorge matando al dragón aparece tan solo a partir del siglo X (Walter, 2003: 81), esta podría ser una fecha aproximada en la que fijar el origen de su leyenda. En realidad, con la incorporación al dossier de San Jorge de la historia 
de la princesa y el dragón se observa el reaprovechamiento de un motivo propio de las biografías de personajes santos con un cierto perfil militar, como sería San Miguel en el Nuevo Testamento y, sobre todo, San Teodoro Terón, el primer santo militar, en cuya leyenda aparece un motivo como este.

En su caso, la escena de la muerte del dragón tampoco está presente en los primeros textos acerca de su vida. Cabe indicar que, en realidad, existen dos Teodoros en la tradición hagiográfica bizantina. Ambos son militares, ambos mártires del primer cristianismo y ambos son originarios de una misma área geográfica. Haldon (2016) subraya la contaminatio entre las historias de los dos Teodoros. Sin embargo, parece más o menos claro que la leyenda del dragón está asociada a Teodoro Terón y constituiría el primer testimonio de la tradición hagiográfica bizantina en el que un santo militar aparece acabando con la vida de un dragón. Este episodio aparecerá en una de las primeras versiones de su martirio, probablemente del siglo VI ( $B H G$ 1761). La breve escena sitúa escuetamente la muerte del dragón en un bosque frondoso situado cerca de la ciudad de Eucaita, en el Helenoponto:

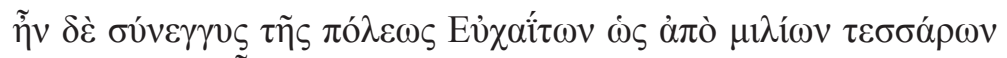

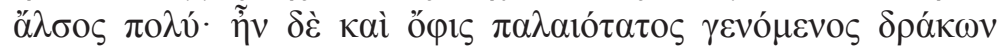

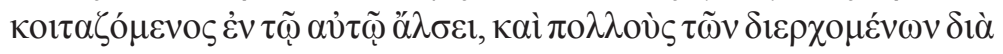

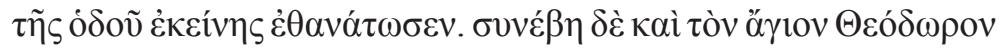

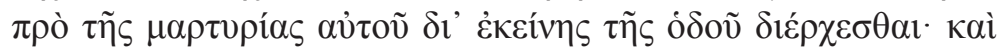

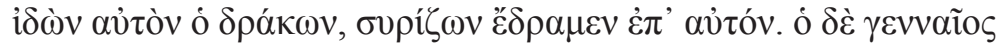

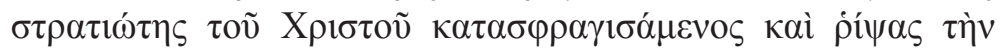

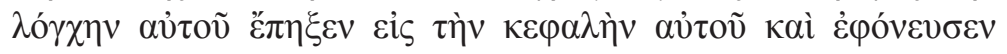

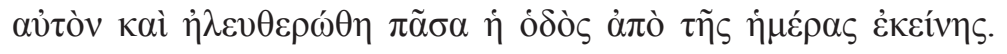
(BHG 1761, 1; Delehaye, 1909: 127)²

2 "Y había muy cerca de la ciudad de Eucaita, como a cuatro millas, un gran bosque. Y había también en aquel bosque una antiquísima serpiente convertida en dragón que habitaba allí y había matado a muchos de los que pasaban por aquel camino. Y sucedió que el mártir Teodoro, antes de su martirio, pasó por aquel camino. Y al verlo, el dragón silbando se abalanzó sobre él. Y el noble soldado de Cristo, tras realizar la señal de la cruz y arrojar su lanza, la clavó en su cabeza y lo mató y todo el camino fue liberado a partir de aquel día." (Traducción del autor) 
Esta escena, además, reaparece con nuevos elementos en otro relato más tardío, probablemente del siglo $\mathrm{X}$ acerca del propio Teodoro ( $\mathrm{BHG}$ 1764). Aquí se contaría cómo Teodoro, tras abandonar el regimiento militar romano acuartelado en Amasea, acaba por arribar hasta un paraje en Eucaita

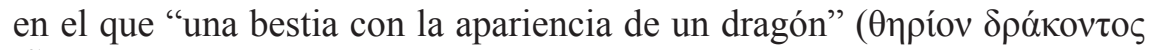
$\left.\varepsilon \tilde{i} \delta \varsigma_{\varsigma}\right)$ impedía el paso a todo aquel que se acercara. Como la propietaria del terreno, la piadosa Eusebia, se encontraba en las inmediaciones, envía unos sirvientes para acoger a Teodoro. Eusebia era una mujer de noble condición, miembro de la familia imperial y, al descubrir que Teodoro era también cristiano, le ofrece su protección y le garantiza total seguridad bajo su techo. Tras oír las palabras de Eusebia, Teodoro decide enfrentarse al dragón:

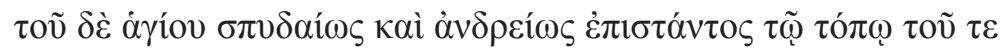

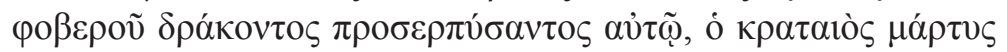

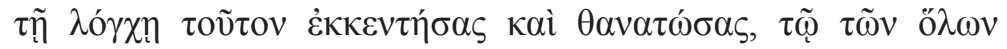

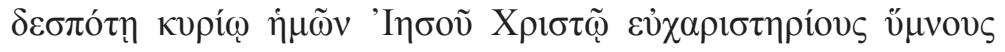

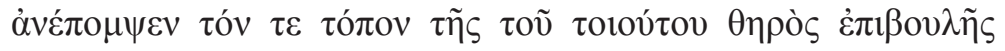

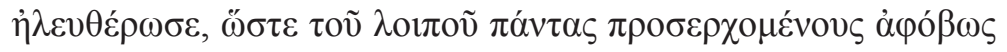

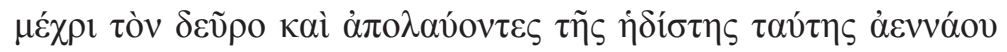

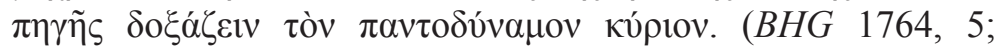
Delehaye, 1909: 189-190)³

La reelaboración del relato del dragón dentro del dossier de Teodoro retoma diferentes elementos de su leyenda y los entremezcla con el objetivo de crear una simbólica historia. Por un lado, la presencia de la piadosa Eusebia parece sintetizar dos personajes diferentes que aparecen en la historia primigenia del mártir. Así, al final del encomio de San Teodoro Terón, escrito por Crisipo de Jerusalén en el siglo V (BHG 1765c) se hace mención a una mujer que recupera los restos del mártir y que Sigalas

3 "Y cuando se presentó el santo decidida y valientemente en el lugar del temible dragón y se puso frente a él, el poderoso mártir lo traspasó con la lanza y lo mató. Envió himnos de gracias a nuestro amo y señor de todas las cosas Jesucristo y liberó el lugar de las maquinaciones de una bestia tal, que desde aquel momento hasta ahora todos los que pasan por allí sin miedo y disfrutan de esta dulcísima fuente que nunca se agota glorifican al señor todopoderoso." (Traducción del autor) 
(1921: 86-87) y Haldon (2016: 65, n. 30) identifican con esta Eusebia. Esto viene propiciado por la aparición de la tal Eusebia en la versión del martirio de Teodoro Terón del siglo VI en la que se leía precisamente la historia del dragón (BHG 1761). Por otro lado, Haldon (2016: 25-27), identifica algunas de las actividades de Eusebia con el modelo piadoso de mujer que en la historia de Teodoro utilizaba Crisipo de Jerusalén en su encomio, el primero de los textos conservados sobre el santo, para animar a la emperatriz Elia Eudocia a financiar la construcción de una iglesia en honor del santo. Así, las actividades de la Eusebia en la versión del martirio del siglo X (BHG 1764) coincidirían en cierto sentido con las de la propia Elia Eudocia.

Por otro lado, el relato de San Jorge y el dragón podría tener su origen en la historia de Teodoro, lo que consolidaría la relación entre el dragón y el perfil del santo militar. La primera representación segura de esta escena se conserva en una iglesia de Capadocia y dataría únicamente del siglo XI (De Jerphanion, 1936: 322; Walter, 1995: 320). Así, la escena del dragón, que, en realidad, se enmarcaría en otra más importante de carácter caballeresco, como el rescate de la princesa por parte del santo, aparecería por vez primera en un manuscrito escrito en georgiano (Walter, 1995: 320-322) y conservado en Jerusalén que contiene tres historias de milagros del santo (Blake, 1934: 361-362).

A partir de ahí se habría incorporado a la leyenda de San Jorge que, desde el siglo V había ido configurándose con diferentes versiones acerca de su vida y su martirio (Delehaye, 1909: 50-63). Así, se habría añadido a los relatos sobre su vida en griego apareciendo en una recopilación de milagros en vida y póstumos del santo que es posible datar entre los siglos XII y XIII (Aufhauser, 1913: 31-33; 62-69). El texto sitúa la acción en una ciudad de Capadocia y afirma que cerca de aquella había un estanque con

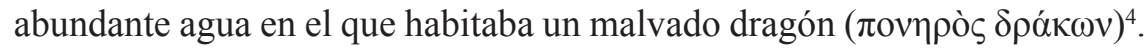
Como este mantenía aterrorizada a la ciudad, el rey decreta ofrecerle cada día una serie de sacrificios humanos, incluyendo al final a su propia hija. De esta manera los ecos de la historia de Perseo y Andrómeda son más que evidentes, a pesar de la opinión contraria de algunos de los investigadores que se ocupaban de analizar la escena, recurriéndose a un elemento de

$4 \quad$ En la versión del milagro del códice Ioasaphaion 308 que reproduce también Aufhauser (1913: 114), escrita en un griego de estilo más popular el dragón aparece catalogado de "grandísimo" ( $\mu \varepsilon \gamma \alpha \lambda \omega ́ \tau \alpha \tau \varsigma \varsigma)$. 
carácter religioso en la Antigüedad como el de los sacrificios que no parece gozar de protagonismo alguno en la tradición hagiográfica bizantina.

El hagiógrafo se recrea en la dramática súplica del rey para liberar a su hija y hace que el relato alcance una trayectoria de tensión ascendente que culmina con la entrada en escena de San Jorge, advertido por Dios del suceso. Al pasar por el estanque en el que la princesa se disponía a ser pasto de la fiera, el santo se acerca y comienza una conversación con la joven hasta que esta accede a relatarle los sucesos que mantenían en vilo a aquella ciudad.

El santo le pide a la princesa que tenga fe en su dios, ya que esta era pagana, aparece una voz divina y, finalmente, se produce la conversión. A continuación, San Jorge se enfrentará al dragón:

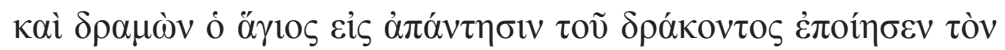

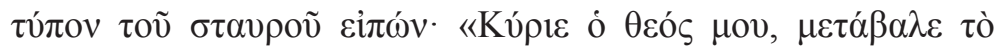

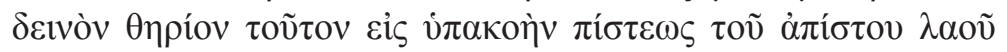

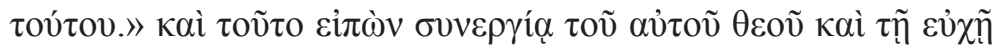

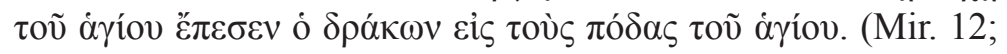
[Aufhauser, 1913: 124-126] $)^{5}$

La escena, sin duda, recuerda en cierto sentido al encuentro en Eucaita de San Teodoro con el dragón. Sin embargo, además del mayor grado de novelización que se da en el caso de San Jorge, existe una diferencia esencial que sitúa la actuación de este último más en la intervención taumatúrgica general de los santos que en el ámbito específico del santo militar. Así, si San Teodoro, como santo militar, acaba con la vida del dragón utilizando su lanza en ambas versiones acerca de la leyenda (BHG 1761 y $B H G$ 1764), San Jorge asesina al animal realizando la señal de la cruz, un gesto que entre los milagros de los santos de época tardo-antigua y bizantina se utilizaba de manera frecuente con una finalidad taumatúrgica y que, en el caso de San Teodoro, solo aparece en la primera de las escenas descritas (BHG 1761), acompañado del lanzamiento de la pica que acaba físicamente con la vida del dragón. El mismo procedimiento para acabar

$5 \quad$ "Y cuando se lanzó el santo al encuentro del dragón hizo la señal de la cruz y dijo: 'Señor, dios mío, convierte a esta fiera terrible por la obediencia de la fe de este pueblo infiel'. Y tras decir esto por la colaboración de su dios y la plegaria del santo cayó el dragón a los pies del santo." 
con esta bestia reaparece en la versión de la leyenda del códex Ioasaphaion 308 (Aufhauser, 1913: 114-126).

En numerosos episodios recogidos en diferentes textos hagiográficos se pueden encontrar escenas similares sin necesidad de tratarse de santos militares. Así, por ejemplo, realizando la señal de la cruz el eremita San Juanicio acaba con la vida de los diferentes dragones que va encontrando en su camino y que pueblan las cuevas que, con su gesto, parece despejar para la ocupación de algún asceta cristiano (BHG 935 y 936).

Por otro lado, en la tradición bizantina existen tres santas conocidas por presentar en sus biografías episodios en los que se encuentran con un dragón y acaban con su vida (White, 2008): Perpetua (BHG 1482), Marina de Antioquía ( $B H G$ 1165) e Isabel de Constantionpla ( $B H G$ 2122). Estos ejemplos de mujeres cazadoras de dragones demuestran la popularidad de la figura del dragón en la hagiografía bizantina media (ss. VIII-XII) que coincide, además, con la aparición y el desarrollo de este motivo entre los diferentes santos militares (White, 2008: 167). De estas tres narraciones, la más interesante para este estudio resulta la de Isabel de Constantinopla por su relación con San Jorge.

Isabel de Constantinopla (o la taumaturga) es una santa monja cenobita de los siglos V-VI, de cuya vida se conservan dos versiones, una más breve ( $B H G$ 2122) (Halkin, 1973; Lackner 1974; Karras, 1996) y otra algo más extensa que, sin embargo, se ha transmitido únicamente de manera fragmentaria ( $B H G$ 2122a). A pesar de tratarse de una santa de época tardo-antigua, el texto dataría como mínimo del siglo XI (Kazhdan 1986: 169-170), aunque, quizá, por la inclusión del milagro del dragón podría retrasarse hasta los siglos XII-XIII ${ }^{6}$. Originaria de la Heraclea Póntica, esta mujer destaca por una temprana carrera monástica que inicia a la muerte de sus padres, momento en que dona su fortuna a la caridad e ingresa en un convento femenino dedicado a San Jorge en Constantinopla, donde su tía paterna era abadesa.

Tras la muerte de la tía, el patriarca constantinopolitano Genadio I (458-471) (Karras, 1996: 128), la nombra abadesa. A partir de ese momento comienza a manifestar una importante habilidad taumatúrgica

$6 \quad$ Sobre la fecha del texto, es importante destacar también que el único manuscrito en el que se conserva, el Conventi B 1 de la Biblioteca nacional de Florencia data del siglo XIV (Halkin, 1973: 251), otro indicio que podría apuntar a una datación algo más tardía de la propuesta por Kahzdan. 
que hará, por ejemplo, que advierta al emperador León I (457-474) del fuego que asolaría parte de Constantinopla en $465^{7}$. Como agradecimiento, el emperador ofreció al monasterio regido por Isabel unas propiedades en el Hebdomón, al suroeste de la ciudad imperial. Allí, tendrá lugar la escena en la que Isabel, rememorando al patrón de su monasterio, San Jorge, acaba con la vida del dragón que mantenía atemorizadas a los habitantes de la zona, como este, realizando la señal de la cruz:

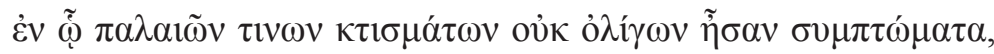

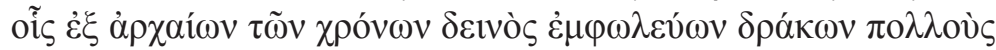

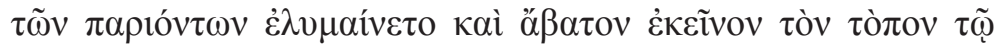

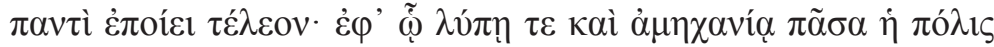

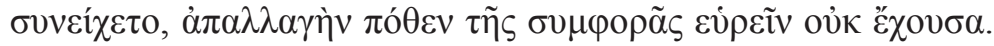

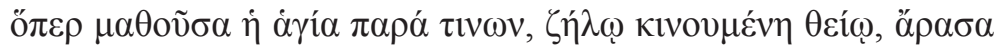

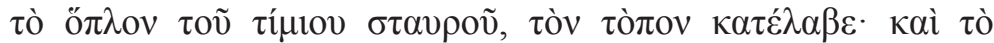

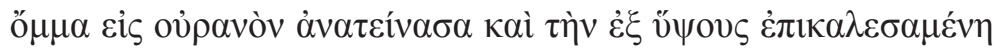

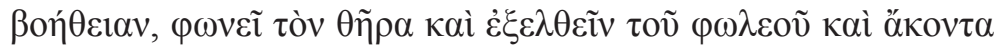

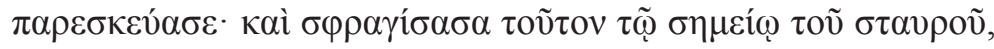

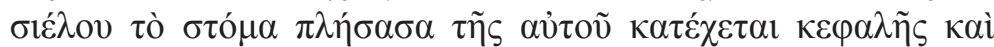

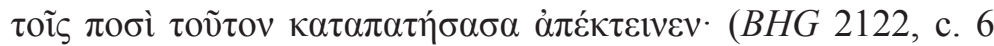
[Halkin, 1973: 259] $)^{8}$

$7 \quad$ El texto destaca cómo la santa es capaz de profetizar este hecho antes incluso que Daniel Estlilita ( $B H G 489)$, santo en cuya biografía se puede leer el episodio de una advertencia similar al emperador León I. Para la edición del texto véase Delehaye (1923: 1-147).

8 "En él había no pocos restos de viejas propiedades, en las que desde tiempos antiguos un temible dragón se escondía, causaba daños a muchos de los que pasaban por allí y hacía que aquel lugar fuera del todo impracticable para todo el mundo. A causa de esto, toda la ciudad se vio afligida por el dolor y la impotencia, puesto que no se sabía cómo encontrar la liberación de este sufrimiento. Cuando la santa se enteró por algunas personas, empujada por un celo divino, con el arma de la honrada cruz en alto, descendió al lugar. Y alzando la vista al cielo y pidiendo ayuda desde lo alto, lanzó un grito a la fiera e hizo que saliera a la fuerza de su guarida. Y haciendo la señal de la cruz sobre ella, y llenándosele la boca de saliva retuvo su cabeza y pisoteándola con sus pies la mató". (Traducción del autor). 
La manera en la que Isabel de Constantinopla acaba con la vida del dragón (la señal de la cruz) confirma la estrecha relación de esta escena con la del dragón que aparecía en la biografía de San Jorge de manera tardía. Sin embargo, existen algunos elementos del relato, como la mención de la situación del dragón en un camino que se había convertido en impracticable porque la bestia atacaba a todos los que pasaban por allí, que recuerdan de manera inequívoca al episodio que aparecía en las dos versiones de la leyenda de Teodoro Terón analizadas unas líneas más arriba. En cualquier caso, la escena de la vida de Isabel de Contantinopla subraya la especial relación del motivo del dragón con la esfera conceptual del santo militar, en este caso en tanto que imitadora del patrón del monasterio del que era abadesa.

Retornando a la estrecha relación entre las escenas de la muerte del dragón en las leyendas de San Teodoro y San Jorge, no cabe duda de la asociación establecida desde la época bizantina media entre ambos santos militares a propósito de este episodio. Diversos ejemplos gráficos del arte religioso de esta etapa en los que aparecen San Teodoro y San Jorge alanceando al dragón pueden dar buena cuenta de este hecho (Walter, 2003b: 95-106). Así, parece producirse una propagación de la idea de que la batalla contra el dragón es un atributo importante del dossier legendario del santo militar.

Este hecho, parece confirmarse con la aparición de escenas más o menos similares que pretenden, mediante su presencia, establecer la relación del santo con la esfera de lo militar. Así, con el objetivo de demostrar esta hipótesis, en las páginas siguientes se van a analizar los casos concretos de San Menas de Egipto y San Eugenio de Trebisonda.

\section{San Menas de Egipto y el cocodrilo}

Entre los diferentes santos llamados Menas en la tradición hagiográfica bizantina (Walter, 1999: 181), San Menas de Egipto es el que recibe un culto más importante, aglutinando algunas de las leyendas y motivos que en principio se asociarían a otros personajes homónimos. Su perfil como santo militar, en todo caso, parece bastante claro, como así lo reflejan las dos versiones griegas de su martirio, la más antigua, probablemente del siglo VI (BHG 1254) (Krumbacher, 1909: 31-43) y la metafrástica (BHG 1250) (De Smedt - Van Hooff - Backer, 1884: 258270). Este status de santo militar lo sigue conservando San Menas en su templo en las inmediaciones del lago Mareotis, cerca de Alejandría, donde 
se ubican algunos de los 13 milagros de una colección (Pomialovskii, 1900; Silvano - Varalda, 2019: 51-85), que puede ser datada como muy pronto en la primera mitad del siglo VII (Narro, 2018: 102-103).

En estos milagros San Menas es descrito en numerosas ocasiones

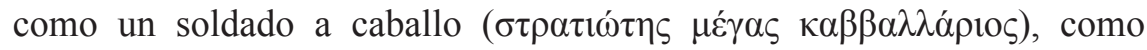
sucede en el célebre milagro 4, el del judío y el cristiano (Devos, 1960) o en el milagro 7, donde se aparece a caballo y bajo la apariencia de un

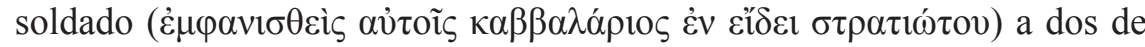
los tres hermanos protagonistas del relato. Precisamente en este milagro es donde se puede apreciar una escena en la que San Menas se enfrenta a un cocodrilo para salvar la vida a uno de estos tres hermanos que portaban a su santuario unos cerditos para ofrecerlos al santo. La narración presenta una serie de diferencias respecto de las leyendas anteriores relacionadas con San Teodoro Terón o San Jorge, pero adapta al contexto geográfico en el que se sitúa el arquetipo del enfrentamiento del santo militar frente al dragón, en este caso un cocodrilo, un animal habitual en la región.

El hagiógrafo relata cómo estos tres hermanos se dirigían al templo de San Menas con los cerditos. En un alto en el camino, se acercan al río, momento en que un cocodrilo ataca a uno de los puercos, lo que provoca la reacción de uno de los hermanos y, con la intención de salvarlos, la intervención del santo:

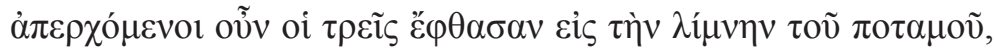

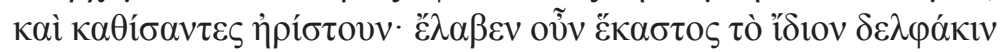

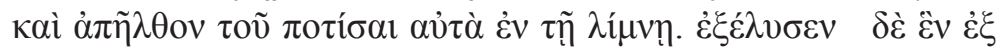

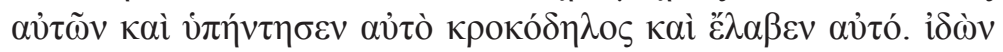

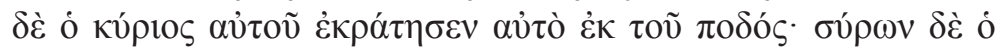

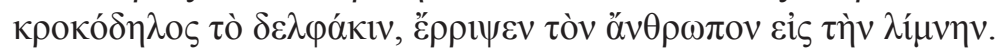

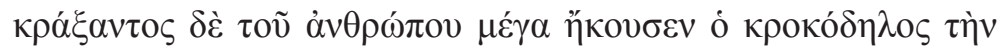

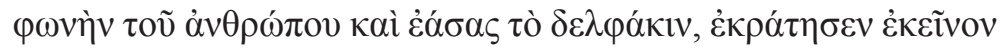

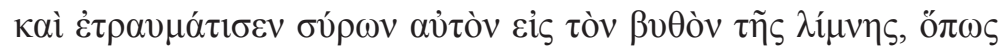

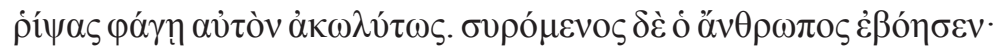

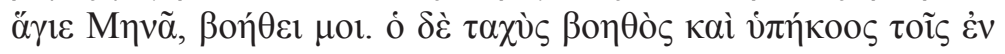

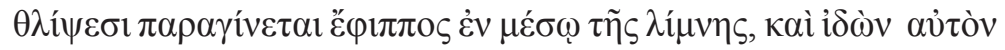

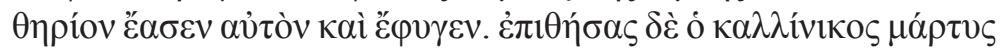

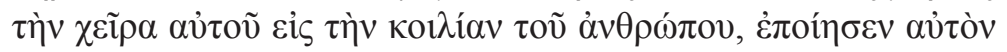

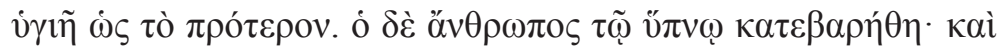

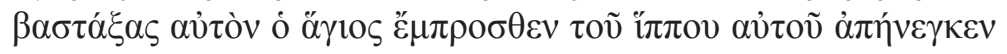




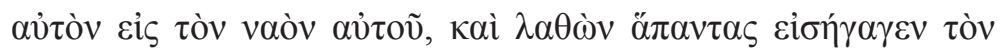

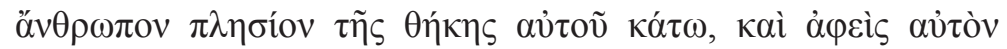
$\dot{\alpha} v \varepsilon \chi \omega ́ \rho \eta \sigma \varepsilon v .{ }^{9}$

La tipología de este milagro está en la línea de las intervenciones atribuidas sobre todo a los santos militares en las que acuden a la asistencia de alguno de sus fieles en alguna situación de peligro. Aunque este tipo de intervenciones no sean exclusivas de este tipo de santos, sí que forman parte de su repertorio habitual. De hecho, en estos trece milagros atribuidos a San Menas, una parte importante de sus intervenciones sigue a grandes rasgos este patrón (Narro, 2018: 106-110). Aquí, el hermano que es arrastrado por el cocodrilo hacia el fondo del lago por intentar salvar al cerdito que llevaba como exvoto al templo de San Menas invoca directamente la ayuda del santo.

En este caso, la lectura del ataque del cocodrilo y su intención de arrastrarlo al fondo del lago se puede interpretar en clave alegórica, atribuyéndole al cocodrilo la evidente encarnación del mal y el diablo con que se identificaba al dragón en la tradición cristiana. La aparición a caballo de San Menas en mitad del lago basta para provocar la huida del cocodrilo, que, al verlo, suelta a su presa para desaparecer en las aguas del lago. A grandes rasgos la escena recuerda las intervenciones de San Teodoro o San Jorge y además reproduce el esquema del dragón -cocodrilo en este casoque habita una masa de agua.

$9 \quad$ "Cuando llegaron los tres al lago del río, se sentaron y desayunaron. Así, cada uno llevó su propio cerdo y fueron a darles de beber en el lago. Pero uno de ellos se soltó y un cocodrilo lo encontró y lo capturó. Su dueño, al verlo, lo sujetó de la pata. Pero el cocodrilo, al tirar del cerdo, arrastró al hombre al lago. Y como el hombre gritaba con fuerza, el cocodrilo escuchó la voz del hombre y, tras soltar al cerdo, lo apresó y lo hirió al tirar de él hacia el fondo del lago, para que, tras arrastrarlo, pudiera comérselo sin problemas. Y el hombre, cuando le tiraba, chilló: «San Menas, ayúdame.» El presto y obediente ayudador de los oprimidos se presentó a caballo en mitad del lago, y al verlo, la bestia, lo soltó y huyó. Y al colocar el glorioso vencedor su mano en la barriga del hombre, lo sanó como al principio. Y el hombre fue vencido por el sueño. Y el santo, levantándolo lo llevó en la parte delantera de su caballo a su templo, y ocultándose a todos condujo al hombre abajo, cerca de su tumba, y, tras dejarlo, se marchó" (Traducción del autor). 
El miedo que parece inspirar al cocodrilo puede ser relacionado con otras escenas taumatúrgicas en el repertorio legendario de otros santos militares que solo con su presencia provocan la fuga del enemigo, normalmente en un contexto bélico, como en el caso de San Demetrio (Lemerle, 1979).

Tras el enfrentamiento con el cocodrilo, el santo manifiesta sus dotes de sanador. De hecho, entre los milagros más extendidos en el ámbito general de la hagiografía, la sanación es sin duda uno de ellos. Aun así, en este caso es mucho más significativa, si cabe, ya que San Menas también puede ser observado desde la perspectiva del santo sanador, sobre todo por la importancia de su templo como centro terapéutico de peregrinación. Esta condición de santo sanador se manifestará en otros milagros de su colección (Mir. 5, 6 y 12), donde incluso realiza una resurrección (Mir. 1) (Narro, 2018: 106-107) y parece ser la razón principal del apogeo de su santuario en las inmediaciones del Mareotis.

Tras la sanación del hombre que había sido atacado por el cocodrilo, San Menas lo lleva hasta su templo donde proseguirá la narración del milagro y su protagonista se reencontrará con sus otros dos hermanos. En este sentido, el regreso del santo a su templo custodiando al sujeto salvado, en este caso concreto de las fauces de un cocodrilo, se reproduce en los milagros 3, 4 y 9 de la colección de San Jorge (Festugière, 1971: 268), protegiendo aquí a una serie de prisioneros que habían sido liberados previamente por el santo.

Como en los casos anteriores, la iconografía del santo completa la visión acerca de él y aporta una información importante del impacto en el imaginario sobre su figura. En los casos anteriores ya se había comentado cómo las primeras representaciones en las que aparecía un santo militar (Teodoro Terón) acabando con la vida de un dragón remitían al siglo VII (Walter, 2003a: 125) y que con el tiempo esa imagen se habría popularizado tanto en el caso individual de cada uno de ellos como en los casos en los que aparecían juntos. Las representaciones de San Menas, sin embargo, suelen presentar al santo flanqueado por dos camellos (Kiss, 1989: 9-13; Cannuyer, 1997).

A estas, se han de añadir otras en las que el santo aparece junto a un cocodrilo (Kaufmann, 1910: 95-97). En este caso, y tratándose de la región de Egipto, se debe de tener en cuenta la posible influencia en la iconografía de San Menas de la antigua historia de Horus y el cocodrilo (Cannuyer, 1997: 147-148). Por otra parte, a pesar de que sus representaciones a caballo, al 
estilo de otros santos militares, no suelen ser demasiado comunes (Walter, 2003a: 186), esta tipología poco a poco se irá imponiendo en la imagen del icono moderno del santo, recordando así sus orígenes y su categoría de santo militar.

\section{San Eugenio de Trebisonda, el Gran Comneno Alejo II y el dragón}

Un caso curioso de evolución en el culto recibido es el de San Eugenio de Trebisonda, un personaje en cuya biografía no se halla en principio relación aparente alguna con el ámbito militar, pero que progresivamente irá asumiendo características propias de estos santos. En realidad, se trata de un mártir de la época de Diocleciano, cuyo culto parece desarrollarse tardíamente, en el período bizantino medio, alcanzando su punto álgido en la época de los Paleólogo (ss. XIII-XV). El primer testimonio de su martirio en la ciudad de Trebisonda lleva la firma de Constantino Luquita (BHG 609), asistente del Gran Commeno Alejo II (1297-1330) y narra la muerte del mártir en la ciudad junto a sus compañeros Valeriano, Canidio y Aquilas (Rosenqvist, 1996: 114-169).

Como se decía anteriormente, en el texto no hay ninguna alusión a Eugenio como soldado del ejército romano, algo que, aunque era habitual en las leyendas de santos militares, tampoco se hallaba, por poner únicamente un ejemplo significativo, en el relato primigenio del martirio de San Demetrio (BHG 496). De hecho, en el martirio de San Eugenio tan solo se puede intuir una aproximación al ámbito militar en la alusión al ofrecimiento que el $d u x$ Lisias hace a los compañeros de Eugenio ni siquiera al propio santo- para enrolarse en el ejército y convertirse en generales (cap. 18; Rosenqvist, 1996: 140-143).

De cualquier manera, sí que podrá observarse su condición de santo militar a título póstumo en virtud de las actuaciones realizadas en defensa de Trebisonda, como su patrón y protector. Así, en la parte final del texto (cap. 32; Rosenqvist, 1996: 164-167) se hace mención a la espada y la fuerza de

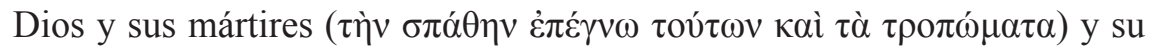
capacidad para derrotar enemigos extranjeros como el líder persa Melik, cuya historia será narrada en la segunda de las colecciones de milagros dedicadas a Eugenio. En estas recopilaciones posteriores, datadas entre los siglos XI y XIV (Rosenqvist, 1996: 28-31), se narran sobre todo curaciones del santo, aunque también tienen un papel importante las intervenciones militares y protectoras de este. 
La primera de estas colecciones consta de 10 milagros que escribió el patriarca de Constantinopla Juan VIII (1064-1075), también conocido como Juan Jifilino (BHG 610), oriundo de la ciudad de Trebisonda (Rosenqvist, 1996: 170-203). La segunda y la tercera de estas recopilaciones de milagros atribuidos a San Eugenio fueron compuestas por Juan Lazarópulo, obispo metropolitano de Trebisonda entre 1364 y 1367 y reciben normalmente el nombre de Logos (BHG 612) y Synopsis (BHG 613) (Rosenqvist, 1996: $30)$.

El Logos contiene cinco milagros cuya temática es bastante variada. El primer milagro versa sobre las diferentes apariciones del santo anunciando a distintos trapezuntinos la fecha de su nacimiento -el 24 de junio, coincidiendo con la festividad de San Juan- con el objetivo de que se celebrara dicha efeméride en la ciudad. Este milagro es aprovechado por Lazarópulo para insertar un largo elogio del Gran Comneno Alejo II (12971330) y la leyenda del dragón venenoso que este había matado en un monte cercano a la ciudad con ayuda del santo.

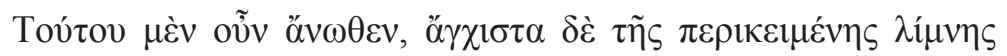

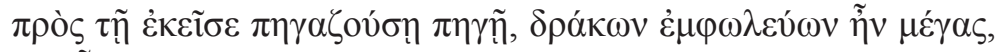

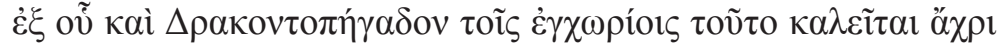

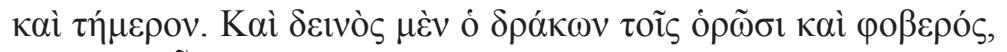

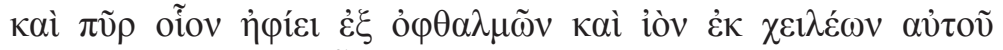

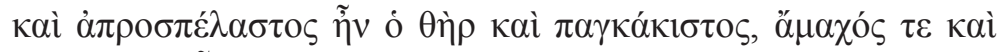

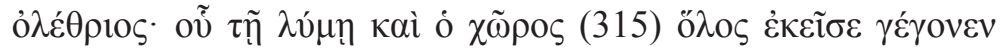

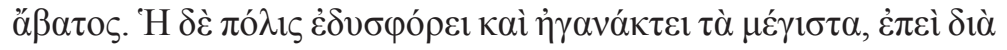

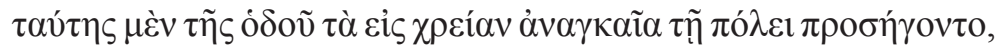

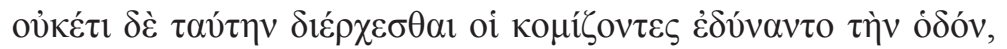

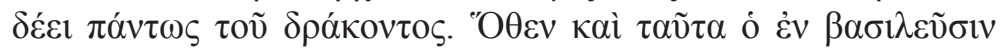

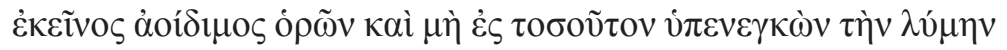

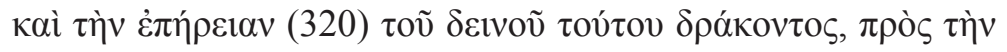

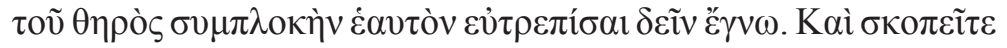

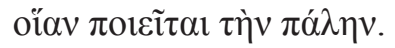

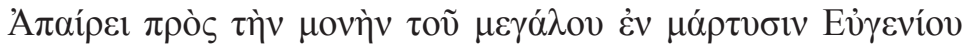

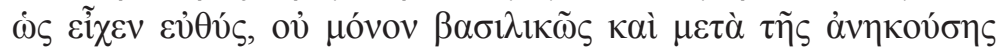

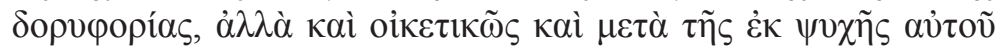

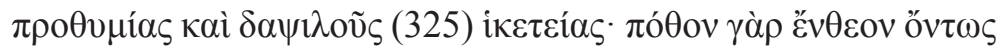

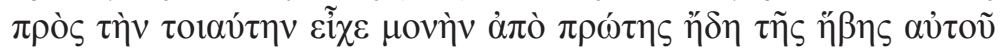

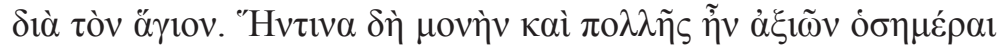




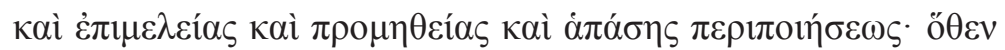

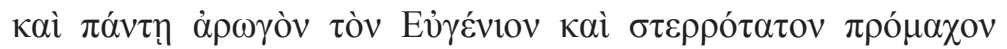

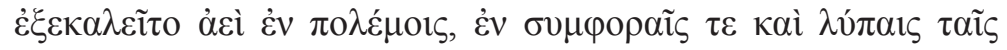

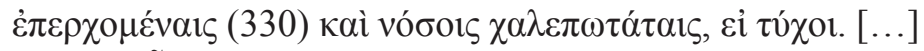

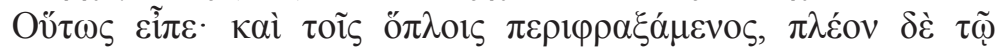

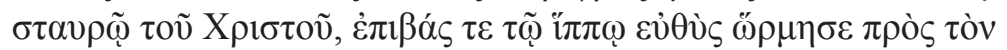

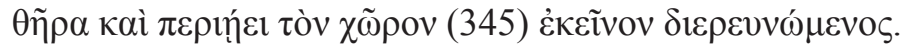

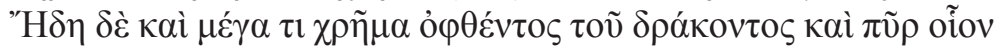

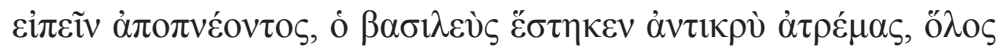

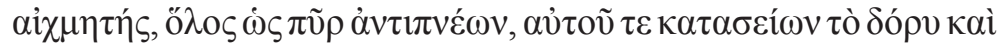

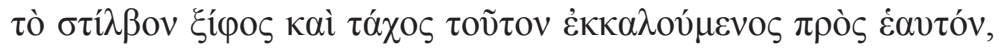

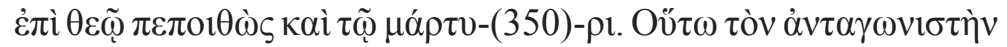

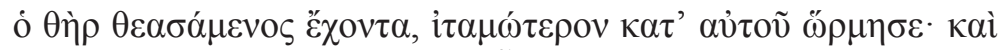

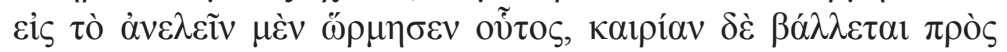

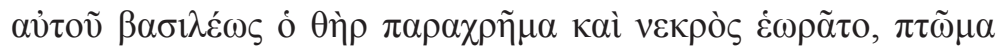

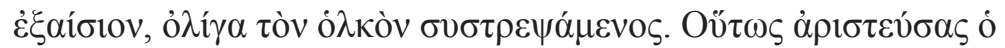

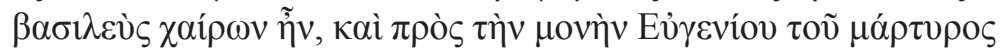

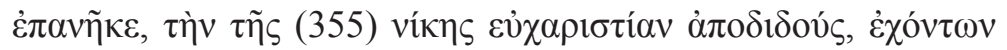

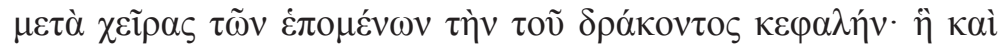

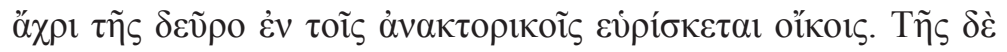

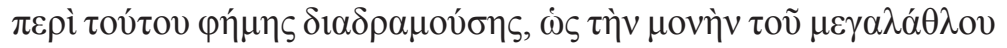

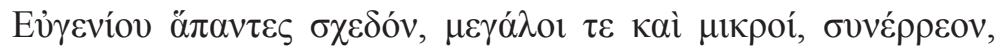

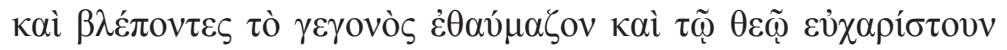

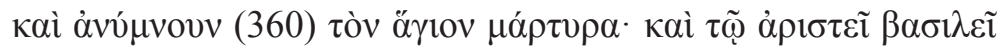

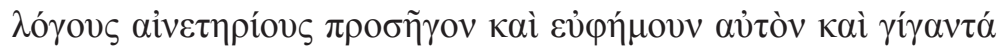

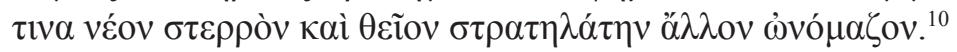

10 "En lo alto de ella [la montaña], muy cerca del lago que se extiende junto a la fuente que allí mana, se ocultaba un gran dragón, de ahí, pues, que incluso hasta hoy a esta se la llame la "Fuente del dragón" entre los habitantes de la región. El dragón era terrible de ver y espantoso, lanzaba fuego de sus ojos y veneno de sus labios y era una bestia inabordable y de lo más malvada, invencible y funesta. Así, a causa de esta desgracia toda la región era inaccesible a partir de ese punto. Y por ello la ciudad sufría y se irritaba en gran medida, porque a través de ese camino llegaban todos los bienes que la ciudad necesitaba para su uso, y los que las transportaban ya no podían atravesar ese camino, sobre todo porque temían al dragón. Y como aquel que en el trono imperial es objeto de celebración viera esto y no soportara tanta desgracia y abuso por parte de este terrible dragón, supo que era necesario que él mismo se preparara para el combate 
El fragmento presenta una serie de elementos importantes a comentar que relacionan tanto la figura del Gran Comneno Alejo II de Trebisonda con la esfera militar y también al propio patrón de la ciudad que acaba

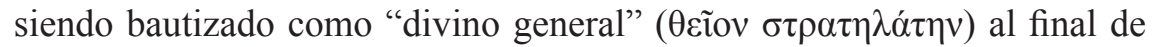
esta sección. En primer lugar, en la descripción del dragón se mezclan elementos propios de diferentes leyendas locales y otros procedentes de los relatos anteriores y del folklore general de la época. Por un lado, la referencia a la fuente del dragón ( $\Delta \rho \alpha \kappa o v \tau o \pi \eta ́ \gamma \alpha \delta o v)$ que aparece al inicio del pasaje destacado parece dotar al relato de un enlace a la realidad y, por tanto, de cierta veracidad. La alusión al lago y a la fuente, además,

con el dragón. ¡Y ya veréis que batalla libró!

Se marchó al templo del grande entre los mártires Eugenio tan rápido como pudo, no solo a la manera de un emperador y con el cuerpo de guardia propio de su posición, sino también a la manera de un sirviente y con buena voluntad en su alma y una importante súplica. Pues ya desde su más tierna juventud había sentido una divina devoción por tal monasterio a causa del santo. Cada día ofrecía a este monasterio una gran atención y cuidado y todo suministro. Y por ello en cada situación invocaba a Eugenio como protector y el más firme luchador en las guerras, en las dificultades y desgracias que le sucedían y en las más graves enfermedades, si por casualidad aparecían. [...]

Así habló y, tras equiparse con sus armas, sobre todo con la cruz de Cristo, y montar a su caballo, se lanzó contra la fiera y se quedó explorando a fondo aquella zona.

Y cuando ya el dragón fue visto con toda su grandeza y exhalando, como decían, fuego, el emperador permaneció firme delante de él, del todo como un lancero, del todo como si exhalara fuego, y agitando su lanza y su brillante espada, se puso a atraer rápidamente a este hacia sí mismo, confiado en dios y en el mártir. Así, al ver la fiera al enemigo que había, se lanzó con ansia contra él. Y este también se lanzó a matarlo, y la fiera recibió al instante un golpe mortal y se vio muerto, desmesurado cadáver, recogiendo un poco su cola. Así, tras vencer, el emperador se alegró y regresó al monasterio del mártir Eugenio para dar gracias por la victoria, llevando entre sus manos la cabeza del dragón que se puede hallar hasta el día de hoy en las dependencias reales.

Y cuando se propagó el rumor sobre este hecho, prácticamente todo el mundo, ricos y pobres, acudieron al monasterio del gran luchador Eugenio, y viendo lo sucedido se maravillaron y dieron gracias a Dios y cantaron himnos al santo mártir. Y llevaron palabras de alabanza para el emperador vencedor y lo elogiaron y lo llamaron al uno "nuevo firme gigante" y al otro "divino general". (Traducción del autor). 
como señala Rosenqvist (1996: 392) evocan claramente la leyenda de San Jorge, aunque la referencia al bloqueo que sufría la región por culpa del dragón que impedía el paso a todo viandante es un motivo que aparecía en las dos versiones comentadas de la leyenda de San Teodoro y el dragón. Finalmente, la descripción del dragón lanzando fuego y escupiendo veneno se adapta a la perfección a la imagen que se tiene de este animal a partir de época medieval, aunque también está en la línea de otros seres similares como el Leviatán de la tradición hebrea o incluso el Tifón de la griega.

En segundo lugar, la actuación de Alejo II de Trebisonda se ve reforzada y amparada por la fuerza de San Eugenio a quien se encomienda visitando su monasterio y por quien el emperador siente una gran devoción. La descripción de la batalla muestra al Gran Comneno con atuendo militar, azuzando al dragón, como sucedía en la escena de Isabel de Constantinopla, para poder asestarle el golpe de gracia que acabará con su vida, como en la leyenda de San Teodoro Terón. La muerte del dragón se reviste de cierto patetismo, haciendo incluso referencia a cómo la bestia replegó un poco su

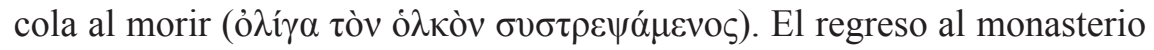
dedicado a San Eugenio se realiza de manera triunfal, con el emperador portando en sus manos la cabeza de la bestia, que Lazarópulo asegura que se conservaba hasta su época en el palacio imperial. Rosenqvist (1996: 393) hace mención a la tradición militar de portar como trofeo la cabeza del enemigo caído (McCornick, 1990: 36 y 46) y relaciona esta escena con el relato de la Crónica de Miguel Panareto (s. XIV) donde refiere cómo Alejo III en 1361 se llevó como trofeo la cabeza del líder turco Cotsialatifes y la paseó por toda la ciudad (Lampsides, 1958: 73, 24-30). En todo caso, es también evidente el eco con la historia de Perseo y la cabeza de la medusa, un ser mitológico relacionado con la morfología de la serpiente que aparece, por si fuera poco, en el repertorio de un héroe conocido por haber acabado con la vida del monstruo marino, escena con la que se suele relacionar el pasaje de San Jorge y el rescate de la princesa de las fauces del dragón. Es bastante posible que Lazarópulo manejara todas estas referencias entremezclando guiños a la tradición literaria clásica y a las leyendas hagiográficas de santos militares.

Además de esta aproximación a la tipología del santo militar que se puede advertir en la inclusión de esta escena, en la iconografía su figura también comienza a experimentar idéntica evolución en ese mismo sentido. Así, durante el gobierno de Alejo II, el santo aparecerá representado a caballo y no frontalmente como lo había sido hasta el momento, al igual 
que el propio emperador. Dicho cambio iconográfico se ha identificado con una tendencia general a la representación de santos a caballo en la producción monetaria de la región en torno al Mar Negro (Rosenqvist, 1996: 79-80). De cualquier modo, no se debería descartar en absoluto la influencia de la progresiva transformación de Eugenio en santo militar y su percepción como tal por parte de la ciudadanía.

En el Logos, además, existen un par de milagros, el cuarto y quinto, en los que San Eugenio interviene para defender a los monjes de su santuario, acercándose de nuevo al ámbito reservado normalmente a los santos militares a través de los prodigios realizados. La tercera y última colección, la Synopsis del propio Lazarópulo habría sido concebida como una continuación de la obra anterior (Rosenqvist, 1996: 32). En ella aparecen 33 milagros en los que se puede observar la evidente evolución de Eugenio de Trebisonda hacia la tipología propia del santo militar. Esta concepción del santo como protector militar de la ciudad responde obviamente a la situación histórica y a la inestabilidad que se vivía en la región y podría constituir una respuesta a la ciudadanía ante la necesidad de seguridad y protección.

Este proceso de evolución de Eugenio de Trebisonda en tanto que santo militar podría ser el responsable de la historia recogida en el milagro 20, donde Lazarópulo relata la aparición de San Eugenio y San Demetrio para la curación de un tal Teodosio, hermano del abad Efraín (Rosenqvist, 1996: 300-305). Este, que se encontraba de viaje y afirmaba llevar consigo tan solo un poco de bálsamo ( $\mu$ v́pov) del santuario de Demetrio en Tesalónica y unos pocos víveres, se ve afectado por una infección de oído, por lo que su hermano decide llevarlo al templo de Eugenio en Trebisonda. Una noche ambos santos, Eugenio y Demetrio, se aparecen a Efraín y Teodoro para procurarle al segundo la curación de su enfermedad. En la visión San Demetrio reconoce el poder superior de Eugenio, puesto que este era el guardián ( $\varphi \rho o v \rho o ́ \varsigma)$ de su ciudad natal y procurador de innumerables beneficios de parte de Dios. Este milagro puede ser entendido como una muestra de una posible concurrencia entre el culto a San Demetrio y a San Eugenio en la ciudad, sobre todo por la fama que el primero ostentaba como santo sanador en Tesalónica en esta época, donde, era venerado como $\mu v \rho o ́ \beta \lambda v \tau o \varsigma$ (literalmente 'brotador de $\mu$ $\rho^{\rho} v^{\prime}$ ') (Walter, 2003a: 80-84).

Este acercamiento se consolida en los milagros 1 y 23 de la Synopsis. En el primero de ellos se cuenta la aparición del santo para ayudar al emperador Basilio I (867-886) a detener un ataque de los iberos 
caucásicos contra Trebisonda. El hagiógrafo relata cómo estos, aliados del rebelde Bardas Focas (muerto en 989), se encontraban dirigiendo su fuerza hacia la región de Trebisonda. San Eugenio se le aparece a caballo ( $\check{\varepsilon} \varphi \imath \pi \pi \varsigma)$ y llevando en su mano una reluciente espada (

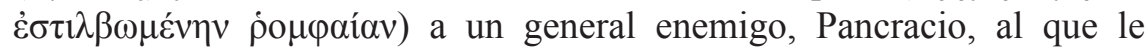
pregunta por qué estaba allí y adónde se dirigía. El general le responde que estaba obedeciendo al rey Bardas Focas y que se dirigía a atacar y destruir Trebisonda. Como contestación, el santo sugiere a Pancracio regresar a casa en tono amenazante para no acabar padeciendo una muerte similar a

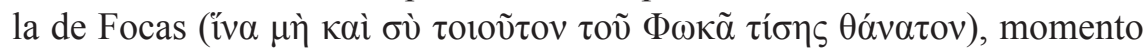
en el que Pancracio toma conciencia de la muerte de su líder y se retira con su ejército atemorizado (Panagiotakes, 1996: 327).

En el 23 se relata el ataque a la ciudad del sultán persa Melik que tiene lugar al principio del reinado del Gran Comneno Andrónico I Gidos (1222-1235). En este caso, Lazarópulo se adorna en la narración de las circunstancias del ataque y en la propia descripción de la ciudad a propósito del ataque de las tropas persas. En este excurso no pasan desapercibidos los numerosos topónimos y lugares de culto dedicados a santos militares en la ciudad (una iglesia de San Procopio y un arroyo de San Jorge) o en sus alrededores (un pueblo llamado San Mercurio o una iglesia dedicada a San Teodoro en el pueblo de Dicaisimón). El ejército persa se dirigía hacia el santuario de San Eugenio, pero el emperador Andrónico escucha en sueños una voz que le afirma que Eugenio -definido como el firme

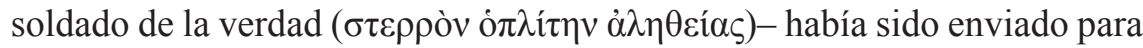
ayudarle a guiar las tropas y conseguir la victoria. En paralelo, Eugenio,

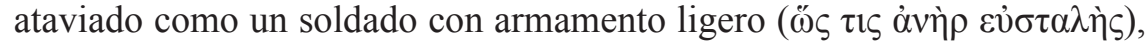
comparece ante el sultán persa, que dormía en el interior de su santuario, para expulsarlo de allí. Así, tras la derrota, Melik se ve obligado a regresar a su territorio sin haber podido hacerse con el control de Trebisonda.

La descripción de San Eugenio como santo militar y su progresiva evolución hacia esta tipología parece bastante clara a tenor de lo expuesto hasta el momento. No obstante, conviene recordar como el punto de inflexión, se encuentra en el primer milagro del Logos de Juan Lazarópulo con el relato de la historia de la asistencia de San Eugenio al Gran Comneno Alejo II en su batalla contra el dragón venenoso que habitaba en un monte cercano a la ciudad.

La escena debe leerse desde una doble perspectiva, aunque siempre en relación con las otras leyendas comentadas. En realidad, el santo no 
interviene directamente para acabar con la vida del dragón, pero sí que asiste a Alejo II para asesinar a la fiera. Inevitablemente, el establecimiento de una asociación de ideas entre esta leyenda y las correspondientes de San Teodoro Terón y de San Jorge parece inevitable en una época (s. XIV) en la que estas eran de sobra conocidas por cualquier fiel, más aún en una ciudad en la que, como se decía, parece haber una notable presencia de santos militares en iglesias e incluso en la toponimia del lugar.

\section{Reflexiones finales}

Como se ha podido comprobar, parece existir una notable presencia de la lucha con el dragón en los repertorios legendarios sobre santos militares. Como se comentaba en un principio, la presencia del dragón o incluso su muerte no es un motivo exclusivo de la tipología de este tipo de santo, aunque sí lo es la manera en la que se le hace frente o acaba con su vida. Desde el relato primigenio, el de San Teodoro, los elementos principales quedan más o menos prefijados. El santo se enfrenta a un temible dragón que habita junto a una fuente, en un lago o masa de agua, y acaba con su vida. Poco a poco, como se ha podido comprobar se altera la historia y se introducen diferentes variaciones o adaptaciones.

Además, del caso de San Jorge, el objetivo principal de este estudio era analizar la presencia de esta escena en otras biografías de santos militares. Para ello se ha recurrido a tres textos distintos. El primero de los casos, el de la Vida de Isabel de Constantinopla es un claro ejemplo de este último hecho. Se trata de una especie de homenaje taumatúrgico que la santa realiza en honor del patrón del monasterio del que era abadesa. El segundo de los casos, el de San Menas y el cocodrilo, representa la adaptación local -al contexto egipcio- del motivo del enfrentamiento del santo al dragón. Por último, el tercero de los pasajes, incide en la adaptabilidad de este motivo. La escena del Gran Comneno Alejo II matando al dragón con la ayuda de San Eugenio, al que se había encomendado, acerca de manera clara y definitiva a este santo al ámbito de lo militar.

Este último testimonio probablemente sea el más interesante, ya que demuestra la capacidad de una escena como esta para hacer evolucionar la tipología de un santo concreto. Este hecho no constituye un fenómeno aislado, ya que en muchos casos los santos son capaces de sufrir diferentes cambios y evoluciones en su culto o sus atribuciones. En este sentido, el simbolismo de la bestia ayudaría a relacionar al santo con una tipología concreta, demostrando la estrecha relación ideológica entre el dragón y el 
santo militar presente en la tradición hagiográfica bizantina.

\section{REFERENCIAS BIBLIOGRÁFICAS}

\section{Fuentes primarias}

AUFHAUSER, J.B. (1913). Miracula S. Georgii, Leipzig: Teubner.

DELEHAYE, H. (1923). Les saints stylites, Bruxelles - Paris: De Brocard.

DEVOS, P. (1960). «Le juif et le chrétien. Un miracle de Saint Ménas », Analecta Bollandiana, 78, 282-285.

FESTUGiÈRE, A.-J. (1971). Collections grecques de miracles. Sainte Thècle. Saints Côme et Damien. Saints Cyr et Jean (extraits). Saint Georges, Paris : A. Picard.

HALKIN, F. (1973). "Sainte Elisabeth d'Héraclée, Abbesse à Constantinople", Analecta Bollandiana, 91, 249-264.

KARRAS, V. (1996). "Life of St. Elisabeth the Wonderworker", in Talbot, A.-M. (1996a) (ed.). Holy Women of Byzantium: Ten Saints' Lives in English Translation, Washington, D.C.: Dumbarton Oaks, 117-135.

KRUMBACHER, K. (1909). Miscellen zu Romanos, München: Akademie der Wissenschaften.

LACKNER, W. (1974). "Zur Vita der Äbtissin Elisabeth von Konstantinopel”, Analecta Bollandiana, 92, 287-288.

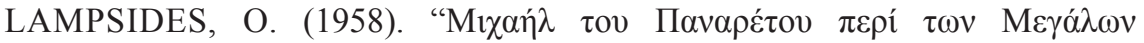

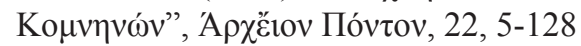

POMIALOVSKII, I. (1900). Житие преподобного Паисия Великого и Тимофея патриарха Александрийского повествование о чудесахсв. великомученика Мины, San Petersburgo.

DE SMEDT, C. - VAN HOOFF, G. - DE BACKER, J. (1884). “Acta Sancti Menae. Martyris Aegyptii”, Analecta Bollandiana, 3, 258-270.

\section{Fuentes secundarias}

ADAMIK, T. (2001). "The Serpent in the Acts of Thomas", en J.N. Bremmer (ed.) The Apocryphal Acts of Thomas, Lovaina: Peeters, 115-124.

AUFHAUSER, J. B. (1911). Das Drachenwunder der heiligen Georg in der griechischen und lateinischen Überlieferung, Leipzig: Teubner.

BLAKE, ROBERT P. (1922-1923). "Catalogue des manuscrits géorgiens de la Bibliothèque patriarcale à Jérusalem », Revue de l'Orient Chrétien, 23, 345-429.

CANNUYER, C. (1997). « Saint Mina aux chameaux : autour des origines d'un iconotype copte », Le monde copte, 27-28, 139. 
DE JERPHANION, G. (1936). Les églises rupestres de Cappadoce. Tome II 1, Paris : P. Geuthner.

DELEHAYE, H. (1909). Les légendes grecques des saints militaires, Paris : A. Picard.

GRANT, R.M. (1999). Early Christians and Animals, Londres-Nueva York: Routledge.

KAUFMANN, C.M. (1910). Ikonographie der Menasampullen mit besonderer Berücksinchtigung der Funde in der Menastadt nebst einem einführenden Kapitel über die neuentdeckten nubischen und aethiopischen Menastexte, El Cairo : F. Diemer.

KAZHDAN, A. (1986). "Hagiographical Notes (13-16)", Byzantion, 56, 148-170. KISS, Z. (1989). Les ampoules de Saint Ménas découvertes à Kôm el-Dikka (1961-1981), Warszawa : PWN.

MCCORNICK, M. (1990). Eternal Victory: Triumphal Rulership in Late Antiquity, Byzantium and the Early Medieval West, Cambridge: Cambridge University Press.

MERKELBACH, R. (1952). "Drache", Rivista di archeologia cristiana, 4, 226250.

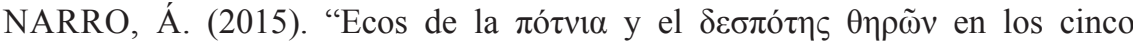
principales Hechos apócrifos de los apóstoles", Minerva, 28, 185-220.-- (2018). “Tipología de los milagros griegos de San Minás (BHG 12561259)", en M. Movellán - J.J. Pomer (eds.) Mite i miracle a les literatures antigues i medievals, Tarragona: Rhemata, 99-110.

PANAGIOTAKES, N.M. (1996). "Fragments of a Lost Eleventh Century Byzantine Historical Work?", in Constantinides, C.N.; Panagiotakes, N.M.; Jeffreys, E. \& Angelou, A.D. (eds.) $\Phi 1 \lambda \varepsilon \lambda \lambda \eta v$. Studies in Honour of Robert Browning, Venezia: Eastmond and James, 321-357.

PASCHALIDIS, S.A. (2018). «Saints et animaux, anticipation du royaume dans la littérature byzantine», en M. Cutino - I. Iribarren - F. Vinel (eds.), La restauration de la création. Quelle place pour les animaux? Actes du colloque de l'ERCAM tenu à Strasbourg du 12 au 14 mars 2015, LeidenBoston : Brill, 213-230.

QUACQUARELLI, A. (1975). Il leone e il drago nella simbolica dell'età patristica, Bari: Università di Bari.

SILVANO, L. - VARALDA, P. (2019). "Per l'edizione dei Miracula sancti Menae (BHG 1256-1269)", Philologia antiqua, 12, 51-85.

SPITTLER, J.E. (2008). Animals in the Apocryphal Acts of the Apostles, Tübingen, Mohr Siebeck.

WALTER, C. (1989). «The Thracian Horseman : Ancestor of the Warrior Saints ?», Byzantinische Forschungen, 14, 659-673. 
--- (1995). “The Origins of the Cult of Saint George”, Revue des Études Byzantines, 53, 295-326.

--- (1999). "Theodore, Archetype of the Warrior Saint", Revue des Études Byzantines, 57, 163-210.

--- (2003a). The Warrior Saints in Byzantine Art and Tradition, Aldershot $\&$ Burlington: Ashgate.

---(2003b). "Saint Theodore and the Dragon", in Entwistle, C. (ed.) Through a Glass Brightly: Studies in Byzantine and Medieval Art and Archaeology Presented to David Buckton, Oxford: University Press, pp. 95-106.

WHITE, M. (2008). "The rise of the dragon in middle Byzantine hagiography", Byzantine and Modern Greek Studies, 32, 149-167. 